\title{
Effects of weekly regrouping of prepartum dairy cows on innate immune response and antibody concentration
}

\author{
P. R. B. Silva, ${ }^{*} \dagger$ J. G. N. Moraes, ${ }^{*} \dagger$ L. G. D. Mendonça, ${ }^{11}$ A. A. Scanavez, ${ }^{*}$ G. Nakagawa, ${ }^{*}$ M. A. Ballou, $\ddagger$ \\ B. Walcheck, $\S$ D. Haines,\# M. I. Endres, $†$ and R. C. Chebel ${ }^{*} \dagger^{2}$ \\ *Department of Veterinary Population Medicine, and \\ †Department of Animal Science, University of Minnesota, St. Paul 55108 \\ ‡Department of Animal and Food Sciences, Texas Tech University, Lubbock 79409 \\ $\S$ Department of Veterinary and Biomedical Sciences, University of Minnesota, St. Paul 55108 \\ \#Western College of Veterinary Medicine, University of Saskatchewan, Saskatoon, SK, S7N 5B4, Canada
}

\begin{abstract}
Objectives were to evaluate the effects of a stable prepartum grouping strategy on innate immune parameters, antibody concentration, and cortisol and haptoglobin concentrations of Jersey cows. Cows $(253 \pm 3 \mathrm{~d}$ of gestation) were paired by gestation length and assigned randomly to the stable (all-in-all-out; AIAO) or traditional (TRD) treatment. In the AIAO treatment, groups of 44 cows were moved into a pen where they remained for $5 \mathrm{wk}$, whereas in the TRD treatment, approximately 10 cows were moved into a pen weekly to maintain stocking density (44 cows for 48 headlocks). Pens were identical in size and design and each pen received each treatment a total of 3 times ( 6 replicates; AIAO, $\mathrm{n}=259$; TRD, $\mathrm{n}=308$ ). A subgroup of cows ( $\mathrm{n}$ $=34$ /treatment) was selected on wk 1 of each replicate from which blood was sampled weekly from d -14 to $14(\mathrm{~d} 0=$ calving $)$ to determine polymorphonuclear leukocyte (PMNL) phagocytosis, oxidative burst, and expression of CD18 and L-selectin, hemogram, cortisol and glucose concentrations, and haptoglobin concentration. Another subgroup of cows ( $\mathrm{n}=40 /$ treatment) selected on wk 1 of each replicate was treated with chicken egg ovalbumin on $\mathrm{d}-21,-7$, and 7 and had blood sampled weekly from d -21 to 21 for determination of immunoglobulin $\mathrm{G}$ anti-ovalbumin. All cows $(\mathrm{n}=149)$ had blood sampled weekly for nonesterified fatty acid (NEFA) and $\beta$-hydroxybutyrate (BHBA) concentrations from $d-21$ to 21 . Treatment did not affect percentage of PMNL positive for phagocytosis and oxidative burst $(\mathrm{AIAO}=64.3 \pm 2.9$ vs. $\mathrm{TRD}=64.3 \pm$ $2.9 \%$ ) and intensity of phagocytosis $[\mathrm{AIAO}=2,910.82$ \pm 405.99 vs. $\mathrm{TRD}=2,981.52 \pm 406.87$ geometric mean
\end{abstract}

Received March 5, 2013

Accepted August 8, 2013.

${ }^{1}$ Current address: Department of Animal Sciences and Industry, 232 Weber Hall, Kansas State University, Manhattan 66506-8028.

${ }^{2}$ Corresponding author: chebe002@umn.edu fluorescence intensity (GMFI)] and oxidative burst $(\mathrm{AIAO}=7,667.99 \pm 678.29$ vs. $\mathrm{TRD}=7,742.70 \pm$ 682.91 GMFI). Similarly, treatment did not affect the percentage of PMNL expressing CD18 $(\mathrm{AIAO}=96.3 \pm$ 0.7 vs. $\mathrm{TRD}=97.8 \pm 0.7 \%)$ and L-selectin $(\mathrm{AIAO}=$ $44.1 \pm 2.8$ vs. $\mathrm{TRD}=45.1 \pm 2.8 \%)$ or the intensity of expression of CD18 (AIAO $=3,496.2 \pm 396.5$ vs. TRD $=3,598.5 \pm 396.9$ GMFI $)$ and L-selectin $($ AIAO $=949.8$ \pm 22.0 vs. TRD $=940.4 \pm 22.3$ GMFI). Concentration of immunoglobulin $\mathrm{G}$ anti-ovalbumin was not affected by treatment $(\mathrm{AIAO}=0.98 \pm 0.05$ vs. $\mathrm{TRD}=0.98$ $\pm 0.05 \mathrm{OD})$. The percentage of leukocytes classified as granulocyte $(\mathrm{AIAO}=38.9 \pm 1.5$ vs. TRD $38.2 \pm$ $1.5 \%)$ and the granulocyte:lymphocyte ratio (AIAO $=$ $0.75 \pm 0.04$ vs. TRD $=0.75 \pm 0.04)$ were not affected by treatment. Concentrations of cortisol (AIAO = $14.95 \pm 1.73$ vs. $\mathrm{TRD}=18.07 \pm 1.73 \mathrm{ng} / \mathrm{mL})$, glucose $(\mathrm{AIAO}=57.6 \pm 1.5 \mathrm{vs} . \mathrm{TRD}=60.0 \pm 1.5 \mathrm{ng} / \mathrm{mL})$, and haptoglobin $(\mathrm{AIAO}=3.09 \pm 0.48$ vs. $\mathrm{TRD}=3.51$ $\pm 0.49 \mathrm{OD})$ were not affected by treatment. According to the current experiment, a stable prepartum grouping strategy does not improve innate immune parameters or antibody concentration compared with weekly prepartum regrouping.

Key words: dairy cow, regrouping, immune response

\section{INTRODUCTION}

Stressors elicit biological responses that are behavioral, neuroendocrine, autonomic, and immune in nature (Moberg, 2000). Several conditions (i.e., elevated temperature humidity index, excessive regrouping, high stocking density) to which prepartum cows are exposed are considered stressors and believed to have profound consequences to health and productive parameters because of their effects on immune, neuroendocrine, and behavioral responses. von Keyserlingk et al. (2008) demonstrated that within the first few hours and days after regrouping, lactating dairy cows that were moved to a new pen had reduced resting time, reduced feed 
intake, and greater rate of displacement from the feed bunk. Accompanied by these behavioral changes, cows that were moved to a different pen had reduced milk yield on the day after regrouping (von Keyserlingk et al., 2008). Stress and pain associated with castration and dehorning cause neutrophilia, reduced secretion of tumor necrosis factor- $\alpha$ by PMNL, and reduced PMNL oxidative burst intensity (Ting et al., 2003; Doherty et al., 2007; Ballou et al., 2013), whereas stress associated with weaning and transport causes a reduction in circulating concentrations of immunoglobulin in pigs (Kojima et al., 2008). The peripartum period is the most delicate phase of a cow's life because of important nutrient balance, hormonal, and immune changes associated with lactogenesis and parturition. Therefore, it has been suggested that prepartum cows subjected to regrouping could suffer more severe negative energy balance and immunosuppression as a consequence of either decreased feed intake or increased concentration of cortisol. Cook and Nordlund (2004) have suggested that, to eliminate stress related to reorganization of social order following regrouping, cows should be moved in groups to a prepartum pen and no new cows should enter these prepartum pens until all cows have calved. This is a similar concept to the all-in-all-out (AIAO) system that is commonly used in other food animalproducing systems (i.e., poultry and swine) to minimize the transmission of infectious diseases.

Reduced feed intake during the periparturient period is associated with increased concentrations of NEFA and BHBA, which have been associated with reduced myeloperoxidase activity of PMNL (Hammon et al., 2006). Furthermore, PMNL of cows diagnosed with metritis have reduced myeloperoxidase activity in the week of parturition (Hammon et al., 2006). On the other hand, exposure to stressors results in increased cortisol concentrations, which may affect concentrations of IgG and IgM (Mallard et al., 1997; Lacetera et al., 2005). Consequently, identifying management strategies that may affect DMI and concentrations of NEFA and BHBA and cause stress is important to reduce immunosuppression during the periparturient period.

The hypotheses of the current experiment were that a prepartum grouping strategy that reduces agonistic behavior (AIAO vs. weekly entry of new cows) would result in reduced cortisol concentration, improved PMNL activity (phagocytosis and oxidative burst), increased expression of adhesion molecules by PMNL (L-selectin and $\beta 2$-integrins), increased IgG concentration in response to an ovalbumin challenge, and increased IgG concentration in colostrum. Therefore, the objectives of the current experiment were to evaluate if a stable prepartum grouping strategy (AIAO) would reduce concentrations of cortisol and improve innate immune parameters and antibody concentration during the peripartum compared with a traditional prepartum grouping strategy in which new cows are introduced weekly into the prepartum pen.

\section{MATERIALS AND METHODS}

Cows used in the current experiment are a subgroup of cows used in a larger experiment (Silva et al., 2013). Detailed description regarding facilities, management, and nutrition may be found in Silva et al. (2013). Briefly, the experiment was conducted from February 2011 to October 2012 in a dairy located in southern Minnesota. Throughout the experiment, Jersey cows were housed in cross-ventilated freestall barns. During the prepartum period ( $\mathrm{d}-28$ to 0 ; $\mathrm{d} 0=$ calving), cows were housed in 1 of 2 freestall pens with 44 stalls and 48 headlocks that were identical in size and design. At the start of each replicate, the target stocking density was $100 \%$ of stalls and $91.6 \%$ of headlocks. From calving to d 21 , all cows were housed in the same freestall pen with 240 stalls and 260 headlocks, and stocking density did not exceed 100 and $91.6 \%$ of stalls and headlocks, respectively. From d 21 until diagnosis of pregnancy $66 \pm 3 \mathrm{~d}$ after AI, cows were housed in freestall barns with 240 stalls and 260 headlocks, and stocking density varied between 110 and $120 \%$ of headlocks and between $119 \%$ and $130 \%$ of stalls. Artificial lighting was provided during the prepartum ( $8 \mathrm{~h}$ of light and $16 \mathrm{~h}$ of dark) and postpartum ( $16 \mathrm{~h}$ of light and $8 \mathrm{~h}$ of dark) periods. All cows received the same TMR during the prepartum period, from calving to d 21, and after d 21 . Diet compositions are described in Silva et al. (2013).

\section{Treatments}

Prepartum Jersey cows ( $\geq$ first lactation) were enrolled in the experiment at $253 \pm 3 \mathrm{~d}$ of gestation. At enrollment, cows were balanced for parity (first or $\geq$ second lactation) and projected 305-d mature-equivalent milk yield and were sequentially assigned to 1 of the 2 study pens. Treatment applied to the study pens in the first replicate was determined randomly (coin toss). Cows assigned to the AIAO ( $\mathrm{n}=6$ replicates with a total of 259 cows) grouping strategy were moved to the prepartum pen in groups of 44 cows (stocking density of $100 \%$ of stalls and $91.6 \%$ of headlocks), but no new cows were added to the AIAO pen until the end of the replicate. Cows assigned to the traditional (TRD, $\mathrm{n}=$ 6 replicates with a total of 308 cows) grouping strategy were moved to the prepartum pen as a group of 44 cows. Weekly thereafter, groups of 2 to 15 cows (median $=9$ cows) were moved to the TRD pen to re-establish the desired stocking density (100\% of stalls and $91.6 \%$ of 
headlocks). At the end of each replicate, a new TRD and AIAO group started but pens were switched to avoid location bias, even though pens were identical in design and had similar temperature and humidity throughout the study (data not shown). There were a total of 6 replicates; thus, each pen had the TRD and AIAO treatment thrice during the experiment.

On the first day of each replicate, a subgroup of cows was chosen for determination of innate immune parameters $(\mathrm{n}=5$ to 6 cows per treatment per replicate) and concentration of antibodies $(\mathrm{n}=6$ to 7 cows per treatment per replicate). The selection of these cows was based on gestation length, to ensure that sampling occurred on the same date for all cows, and BCS. Therefore, 68 cows $(\mathrm{n}=34$ /treatment $)$ were used for evaluation of innate immune parameters, hemogram, cortisol and glucose concentrations, and haptoglobin concentration. A total of 80 cows $(n=40 /$ treatment $)$ were used for evaluation of antibody concentration. All cows ( $\mathrm{n}=74 /$ treatment) had blood sampled to determine concentrations of NEFA and BHBA. Only data from these 148 cows is presented herein.

\section{BCS and Locomotion Scores}

At enrollment and $1 \pm 1,28 \pm 3$, and $56 \pm 3 \mathrm{~d}$ postpartum, all cows were scored for body condition $(1=$ emaciated and $5=$ obese; 0.25-unit increments, as described by Ferguson et al., 1994) and locomotion $(1=$ normal locomotion and $5=$ severely lame, as described by Sprecher et al., 1997).

\section{Innate Immune Response Assays}

In a subgroup of cows (AIAO $=34$ and $\mathrm{TRD}=34)$, ex vivo innate immune parameters were evaluated on $\mathrm{d}-14 \pm 1,-7 \pm 1,0 \pm 1,7 \pm 1$, and $14 \pm 1$ as described by Hulbert et al. (2011). Samples were collected into heparinized evacuated tubes (Becton Dickinson Vacutainer Systems, Franklin Lakes, NJ). Expression of L-selectin and CD18 by peripheral PMNL was determined by indirect immunofluorescence staining. Briefly, the assay consisted of incubating $200 \mu \mathrm{L}$ of whole blood at $4^{\circ} \mathrm{C}$ for $30 \mathrm{~min}$ with $5 \mu \mathrm{g} / \mathrm{mL}$ of anti-bovine CD62L (DU1-29, VMRD Inc., Pullman, WA) monoclonal antibody produced in mouse or $2.5 \mu \mathrm{g} / \mathrm{mL}$ of anti-bovine CD18 (BAQ30A, VMRD Inc.) monoclonal antibody produced in mouse. Erythrocytes were lysed with hypotonic PBS solution before being incubated with an anti-mouse IgG-fluorescein isothiocyanate (FITC) secondary polyclonal antibody (AbD Serotec, Raleigh, NC) diluted 1:400 in PBS solution (SigmaAldrich, St. Louis, MO). After washing the cells with PBS, samples were analyzed by flow cytometry. Blood samples from nondiseased cows were used as positive and negative controls in all assays. Negative controls consisted of incubating $200 \mu \mathrm{L}$ of PBS solution instead of the monoclonal antibody. Phagocytic and oxidative burst activity of peripheral PMNL were determined upon challenge with enteropathogenic bacteria (Escherichia coli 0118:H8) as described by Hulbert et al. (2011). Briefly, the assay to determine phagocytosis and oxidative burst consisted of incubating $200 \mu \mathrm{L}$ of whole blood with $40 \mu \mathrm{L}$ of $100 \mu M$ dihydrorhodamine 123 (Molecular Probes/Invitrogen, Eugene, OR), an oxidative-sensitive indicator, and $40 \mu \mathrm{L}$ of fluorescently labeled bacteria $\left(10^{9} \mathrm{cfu} / \mathrm{mL}\right)$ at $38.5^{\circ} \mathrm{C}$ for $15 \mathrm{~min}$, with surface bacteria fluorescence removed using Trypan Blue solution (0.4\%; Sigma-Aldrich). After washing with milliQ water (EMD Millipore, Billerica, MA) to remove excess dye, erythrocytes were lysed by the addition of hyper-concentrated PBS solution (SigmaAldrich). Finally, the cells were resuspended in PBS solution for immediate flow cytometry analyses. Blood from nondiseased cows were used as positive and negative controls. Unlabeled bacteria were used as negative controls for the phagocytosis assay and samples that received no dihydrorhodamine 123 served as negative controls for the oxidative burst assay. All flow cytometry data were collected on a BD FACSCanto II (BD Biosciences, Franklin Lakes, NJ) and analyzed using FlowJo 7.6.4 software (Tree Star Inc., San Carlos, CA). The PMNL population was identified on basis of forward- and side-scattered properties. After strictly gating the PMNL population, data from 3 parameters were collected for analysis: forward scatter, side scatter, and $\log$ fluorescence. Data are reported as PMNL intensity of phagocytosis, oxidative burst, and expression of CD18 and L-selectin molecules expressed in geometric mean fluorescence intensity (GMFI). Phagocytic and adhesion molecule intensity was an indirect indication of the number of phagocytosed bacteria and adhered molecules by PMNL, respectively. Oxidative burst intensity was an indirect indication of the amount of reactive oxygen species produced via oxidation of dihydrorhodamine 123. Furthermore, percentages of PMNL positive for phagocytosis, oxidative burst, and expression of CD18 and L-selectin molecules were calculated.

\section{Hemogram}

Blood sampled on $\mathrm{d}-14 \pm 1,-7 \pm 1,0 \pm 1,7$ \pm 1 , and $14 \pm 1$ were used for hemogram. Samples collected into evacuated tubes with EDTA (Becton Dickinson Vacutainer Systems) were analyzed using a Vet Scan HM2 (Abaxis, Union City, CA). Complete blood count was performed but only data referent to concentration of granulocytes relative to total leuko- 
cytes and the granulocytes to lymphocytes ratio are reported.

\section{Antibody Concentration and Assay}

Cows received injections of $1 \mathrm{mg}$ of chicken egg ovalbumin (Sigma-Aldrich) diluted in Quil A adjuvant (0.5 mg of Quil A/mL of PBS; Accurate Chemical \& Scientific Corp., Westbury, NY) on d $-21 \pm 3,-7 \pm 3$, and $7 \pm 3$. Blood was sampled weekly from $\mathrm{d}-21 \pm 3$ to 21 \pm 3 into evacuated tubes without anticoagulant (Becton Dickinson Vacutainer Systems) for determination of IgG anti-ovalbumin in serum by ELISA as described by Mallard et al. (1997). Only cows that received at least 2 doses of chicken egg ovalbumin, $\mathrm{d}-21 \pm 3$ and $-7 \pm 3$, were retained for the analysis.

\section{Cortisol, Metabolites, and Haptoglobin Assays}

Blood samples collected into evacuated tubes without anticoagulant (Becton Dickinson Vacutainer Systems) on $\mathrm{d}-14 \pm 1,-7 \pm 1,0 \pm 1,7 \pm 1$, and $14 \pm 1$ were used for determination of serum cortisol concentrations using a solid-phase RIA kit (Coat-a-Count, Siemens Medical Solutions Diagnostics, Los Angeles, CA). The intra- and interassay coefficients of variation $(\mathbf{C V})$ were 5.8 and $11.7 \%$, respectively.

Concentrations of NEFA were determined using a colorimetric assay (Wako Chemicals USA, Richmond, VA; Ballou et al., 2009) and concentrations of BHBA were determined enzymatically (Ranbut, Randox Laboratories, Antrim, UK; Ballou et al., 2009). Samples for determination of NEFA and BHBA were collected into evacuated tubes containing EDTA (Becton Dickinson Vacutainer Systems) on d $-18 \pm 3,-11 \pm 3,-4 \pm 3,3$ $\pm 3,10 \pm 3,11 \pm 3$, and $18 \pm 3$. A plate reader (Spectramax 340; Molecular Devices, Sunnyvale, CA) was used to measure the absorbance for the colorimetric and enzymatic assays. Control serum (Randox Control Sera, Antrim, UK) was used for the NEFA and BHBA assays. The intraassay $\mathrm{CV}$ were 4.5 and $8.1 \%$ and the interassay CV were 8.2 and $10.1 \%$ for the NEFA and BHBA assays, respectively. Glucose concentration was determined by enzymatic reaction (Stanbio Laboratory, Boerne, TX). The intraassay CV were 5.3 and $9.1 \%$ for the glucose assay, respectively.

Haptoglobin concentration was determined by a colorimetric procedure as described by Hulbert et al. (2011) using a plate reader (Spectramax 340; Molecular Devices) to measure the absorbance. Samples were collected into evacuated tubes containing EDTA (Becton Dickinson Vacutainer Systems) on d $-14 \pm 1,-7 \pm 1$, $0 \pm 1,7 \pm 1$, and $14 \pm 1$. The intra- and interassay CV were 4.1 and $9.8 \%$, respectively.

\section{Clinical Examination and Definitions of Diseases}

Cows were examined on $\mathrm{d} 1,4 \pm 1,7 \pm 1,10 \pm 1$, and $13 \pm 1$ for the diagnosis of retained fetal membranes, metritis, and acute metritis. Retained fetal membranes was defined as retention of fetal membranes past $24 \mathrm{~h}$ postpartum. Metritis was defined as cows with watery, pink/brown, and fetid uterine discharge. Cows with symptoms of metritis and rectal temperature $>39.5^{\circ} \mathrm{C}$, or anorectic, or depressed were considered to have acute metritis (LeBlanc, 2010). All cows were observed once daily for displacement of abomasum and thrice daily for mastitis throughout their lactation. Data regarding incidence of displacement of abomasum and mastitis from study d 0 to 60 are reported herein.

On d $30 \pm 3$, the subgroup of 68 cows used to evaluate innate immune responses was examined for sub-clinical endometritis $(\geq 10 \%$ of cells in the uterine cytology were PMNL; Kasimanickam et al., 2004) using the cytobrush technique (Cytobrush Plus, Cooper Surgical Inc., Trumbull, CT). After sample collection, the cytobrush was rolled onto a clean glass slide, which was stained with modified Wright-Giemsa stain (Protocol-Hema3, Biochemical Sciences, Swedesboro, NJ). Slides were evaluated twice at $400 \times$ magnification by one examiner who was blinded to the treatments. This same subgroup of cows was examined for clinical endometritis (exudate consisting of $\geq 50 \%$ of pus) using the Metricheck device (Simcro, Hamilton, New Zealand; McDougall et al., 2007) on study d $35 \pm 3$.

\section{Production Parameters}

Cows were milked thrice daily. Monthly, milk yield, milk fat and protein contents, and SCC were recorded for individual cows during the official DHIA test. Data regarding milk yield, milk fat and protein contents, and SCC were collected from study d 0 to 305 . Energycorrected milk was calculated for each cow using the formula (Orth, 1992)

$$
\begin{gathered}
\operatorname{ECM}(\mathrm{kg})=[(\mathrm{kg} \text { of milk }) \times 0.327]+[(\mathrm{kg} \text { of fat }) \\
\times 12.95]+[(\mathrm{kg} \text { of protein }) \times 7.2] .
\end{gathered}
$$

All cows received recombinant bST (500 mg of Posilac; Elanco Animal Health, Greenfield, IN) every $10 \mathrm{~d}$ starting $57 \pm 3 \mathrm{~d}$ postpartum.

\section{Statistical Analysis}

The experiment had a randomized design with pen as the experimental unit. In the first replicate, a coin was tossed to determine the treatment of each of the 2 study 
Table 1. Percentage of cows calving male calves and twin births and incidence (\%) of peripartum diseases of the subgroups of traditional (TRD) and all-in-all-out (AIAO) cows used to evaluate innate immune parameters and antibody concentration ${ }^{1}$

\begin{tabular}{lrccc}
\hline Item & TRD & AIAO & $\begin{array}{c}\text { Adjusted odds ratio } \\
(95 \% \text { CI })\end{array}$ & $P$-value \\
\hline Male calf & 50.0 & 46.2 & $0.86(0.39,1.89)$ & 0.67 \\
Twins & 3.1 & 4.6 & $1.50(0.19,12.06)$ & 0.68 \\
Retained fetal membranes & 7.8 & 11.1 & $1.51(0.33,6.91)$ & 0.56 \\
Metritis & 15.6 & 16.9 & $1.11(0.34,3.64)$ & 0.85 \\
Acute metritis & 1.6 & 4.6 & $3.21(0.15,69.41)$ & 0.42 \\
Endometritis & 10.3 & 10.3 & $0.95(0.13,6.79)$ & 0.96 \\
Subclinical endometritis & 20.7 & 24.1 & $1.89(0.41,8.77)$ & 0.42 \\
Displacement of abomasum & 3.3 & 1.7 & $0.50(0.03,8.02)$ & 0.59 \\
Mastitis & 12.7 & 12.9 & $0.88(0.19,4.13)$ & 0.86 \\
\hline
\end{tabular}

${ }^{1} \mathrm{TRD}=$ weekly entry of new cows into the prepartum pen; AIAO $=$ no entry of new cows in the prepartum pen. Target stocking density was $100 \%$ of stalls and $91.6 \%$ of headlocks.

pens. In each of the replicates cows were balanced for parity (first or $\geq$ second lactation) and projected 305-d mature-equivalent milk yield and were assigned to 1 of the 2 study pens. The sample size was calculated based on the expected reduction in mean intensity of oxidative burst and reduction in mean intensity of phagocytosis on the day of calving. Thus, a sample size of 6 would be enough to demonstrate statistical difference when intensity of oxidative burst was reduced by $38 \%$ for cows in the TRD compared with cows in the AIAO treatment, when the standard deviation of intensity of oxidative burst on the day of calving is 2,000 GMFI (Mendonça et al., 2013).

Statistical analyses were conducted using SAS software (version 9.2; SAS/STAT, SAS Inst. Inc., Cary, $\mathrm{NC}$ ). Binomial data were analyzed by logistic regression using the GLIMMIX procedure with the binary distribution and logit function. Continuous data were analyzed by ANOVA using the MIXED procedure. In all models, treatment (TRD vs. AIAO), replicate ( 1 to 6 ), and the interaction between treatment and replicate were included as a fixed effect. Pen was included as the random effect and treatment was nested within pen and replicate. For analysis of repeated measurements the repeated statement was used, the structure of covariance (auto-regressive, unstructured, or compound symmetry) was chosen according to the Bayesian Akaike information criteria, and time and the interaction between treatment and time were included in the model as fixed effects. Statistical significance was defined as $P \leq 0.05$ and statistical tendencies as $0.05<P \leq 0.10$.

\section{RESULTS}

The percentages of cows calving male calves $(P=$ $0.67)$ and twins $(P=0.68)$ were not different between treatments (Table 1). Similarly, the incidences of retained fetal membranes $(P=0.56)$, metritis $(P=0.85)$, acute metritis $(P=0.42)$, endometritis $(P=0.96)$, subclinical endometritis $(P=0.42)$, displacement of abomasum $(P=0.59)$, and mastitis $(P=0.86)$ were not different between treatments (Table 1 ).

Treatment had no effect $(P=0.66)$ on BCS (AIAO $=2.80 \pm 0.05$ vs. TRD $=2.84 \pm 0.05)$. Yields of milk $(\mathrm{AIAO}=29.38 \pm 0.98$ vs. $\mathrm{TRD}=28.33 \pm 0.99 \mathrm{~kg} / \mathrm{d}$; $P=0.47)$, fat $(\mathrm{AIAO}=1.32 \pm 0.04$ vs. $\mathrm{TRD}=1.29$ $\pm 0.04 \mathrm{~kg} / \mathrm{d} ; P=0.64)$, and protein $($ AIAO $=1.09$ \pm 0.04 vs. TRD $=1.06 \pm 0.04 \mathrm{~kg} / \mathrm{d} ; P=0.59)$ were not different between treatments. Consequently, no differences were observed between treatments regarding $3.5 \%$ FCM $(\mathrm{AIAO}=37.56 \pm 1.21$ vs. $\mathrm{TRD}=36.72 \pm$ $1.22 \mathrm{~kg} / \mathrm{d} ; P=0.64)$ or ECM $(\mathrm{AIAO}=34.93 \pm 1.14$ vs. TRD $=33.98 \pm 1.15 \mathrm{~kg} / \mathrm{d} ; P=0.57)$. Similarly, SCS did not $(P=0.31)$ differ between treatments $($ AIAO $=$ $2.73 \pm 0.16$ vs. $\mathrm{TRD}=2.97 \pm 0.16)$.

\section{Innate Immune Parameters and Antibody Concentration}

Treatment $(P=0.75)$ and the interaction between treatment and day $(P=0.68)$ did not affect the percentage of leukocytes classified as granulocytes (Table $2)$. Similarly, the granulocytes:lymphocytes ratio was not affected by treatment $(P=0.93)$ or by the interaction between treatment and day $(P=0.63$; Table $2)$. Treatment $(P=0.98)$ and the interaction between treatment and day $(P=0.53)$ did not affect the percentage of PMNL that were positive for phagocytosis and oxidative burst (Table 2). Among PMNL positive for phagocytosis and oxidative burst, treatment did not affect the intensity of phagocytosis $(P=0.94$; Table 2 ) or the intensity of oxidative burst $(P=0.99$; Table 2 ). The percentage of PMNL expressing CD18 was not affected by treatment $(\mathrm{AIAO}=96.3 \pm 0.7$ vs. $\mathrm{TRD}=$ $97.8 \pm 0.7 \% ; P=0.17)$ or by the interaction between treatment and day $(P=0.54)$. Similarly, intensity of ex- 
Table 2. Effects of prepartum grouping strategy on hemogram and innate immune parameters, antibody concentration, and NEFA and BHBA concentrations

\begin{tabular}{|c|c|c|c|c|c|}
\hline Item & \multicolumn{2}{|c|}{ Treatment $(\text { Trt })^{1}$} & \multicolumn{3}{|c|}{$P$-value } \\
\hline Granulocytes, $10^{9} \times$ cells $/ \mathrm{L}$ & $3.72 \pm 0.17$ & $3.97 \pm 0.17$ & 0.33 & $<0.01$ & 0.13 \\
\hline Granulocyte:lymphocyte & $74.54 \pm 4.28$ & $75.07 \pm 4.28$ & 0.93 & $<0.01$ & 0.63 \\
\hline PMNL leukocytes & & & & & \\
\hline Phagocytosis and oxidative burst positive, $\%$ & $64.33 \pm 2.93$ & $64.25 \pm 2.92$ & 0.98 & 0.01 & 0.53 \\
\hline IgG anti-ovalbumin, optical density $\times 10^{3}$ & $984.1 \pm 54.4$ & $977.4 \pm 53.0$ & 0.93 & $<0.01$ & 0.24 \\
\hline $\mathrm{NEFA}, \mu \mathrm{mol} / \mathrm{L}$ & $224.9 \pm 16.7$ & $231.7 \pm 16.6$ & 0.78 & $<0.01$ & 0.72 \\
\hline $\mathrm{BHBA}, \mu \mathrm{mol} / \mathrm{L}$ & $398.9 \pm 32.7$ & $418.3 \pm 32.4$ & 0.18 & $<0.01$ & 0.34 \\
\hline
\end{tabular}

${ }^{1}$ TRD (traditional prepartum grouping strategy) = weekly entry of new cows into the prepartum pen; AIAO (all-in-all-out prepartum grouping strategy $)=$ no entry of new cows in the prepartum pen. Target stocking density was $100 \%$ of stalls and $91.6 \%$ of headlocks. Results are reported as $\mathrm{LSM} \pm \mathrm{SE}$.

${ }^{2}$ Day $=$ days relative to calving.

${ }^{3}$ Percentage of leukocytes classified as granulocytes.

${ }^{4}$ Geometric mean fluorescence intensity.

pression of CD18 was not affected by treatment (AIAO $=3,496.2 \pm 396.5$ vs. TRD $=3,598.5 \pm 396.9$ GMFI; $P=0.60)$ or by the interaction between treatment and day $(P=0.21)$. The percentage of PMNL expressing Lselectin was not affected by treatment $(\mathrm{AIAO}=44.1 \pm$ 2.8 vs. $\mathrm{TRD}=45.1 \pm 2.8 \% ; P=0.81)$ or by the interaction between treatment and day $(P=0.56)$. Intensity of L-selectin expression was not affected by treatment $(\mathrm{AIAO}=949.8 \pm 22.0$ vs. $\mathrm{TRD}=940.4 \pm 22.3 \mathrm{GMFI}$; $P=0.84)$ or by the interaction between treatment and day $(P=0.48)$. Finally, IgG anti-ovalbumin concentration was not affected by treatment $(P=0.93)$ or by the interaction between treatment and day $(P=0.24$; Table 2). The concentration of IgG in the colostrum did not $(P=0.41)$ differ between treatments $($ AIAO $=$ $85.26 \pm 5.42$ vs. $\mathrm{TRD}=93.38 \pm 5.73 \mathrm{~g} / \mathrm{dL})$.

\section{Cortisol Concentration, Metabolic Parameters, and Haptoglobin}

Treatment did not $(P=0.48)$ affect serum cortisol concentration. On the other hand, we observed a tendency $(P=0.09)$ for the interaction between treatment and day to affect the serum cortisol concentration: on $\mathrm{d}-7$, the cortisol concentration was higher for TRD than for AIAO cows (Figure 1). Concentration of glucose was not affected by treatment $(P=0.28)$ or by the interaction between treatment and day $(P=$ 0.11 ; Figure 2). Similarly, treatment $(P=0.78)$ and the interaction between treatment and day $(P=0.72)$ did not affect the concentrations of NEFA (Table 2). Concentration of BHBA was not $(P=0.18)$ different between treatments and was not $(P=0.34)$ affected by the interaction between treatment and day (Table 2).
Concentration of haptoglobin was not $(P=0.57)$ different between treatments, but the interaction between treatment and day tended $(P=0.10)$ to affect haptoglobin concentration because, on d 14 after calving, the haptoglobin concentration of TRD cows was higher than that of AIAO cows (Figure 3 ).

\section{DISCUSSION}

In the current experiment, the percentage of leukocytes classified as granulocytes and the ratio of granu-

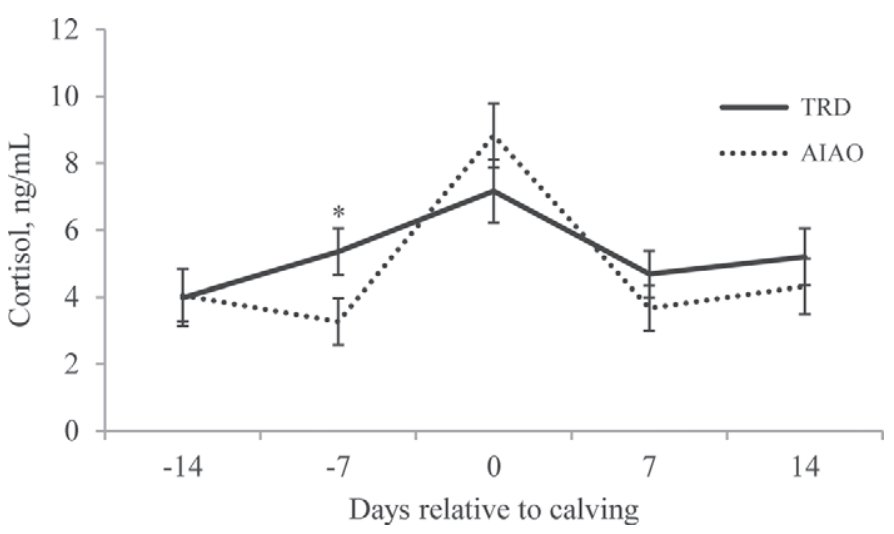

Figure 1. Effect of treatment on cortisol concentrations during the peripartum period. Traditional prepartum grouping strategy (TRD) $=$ weekly entry of new cows into the prepartum pen; all-in-all-out prepartum grouping strategy $(\mathrm{AIAO})=$ no entry of new cows in the prepartum pen. Target stocking density was $100 \%$ of stalls and $91.6 \%$ of headlocks. Treatment $(P=0.48)$ did not affect cortisol concentration from $14 \mathrm{~d}$ before to $14 \mathrm{~d}$ after calving, but the interaction between treatment and days relative to calving tended $(P=0.09)$ to affect concentration of cortisol, because on d 7 before calving $\left(^{*}\right)$ cortisol concentration was $(P=0.04)$ higher for TRD cows than for AIAO cows. 


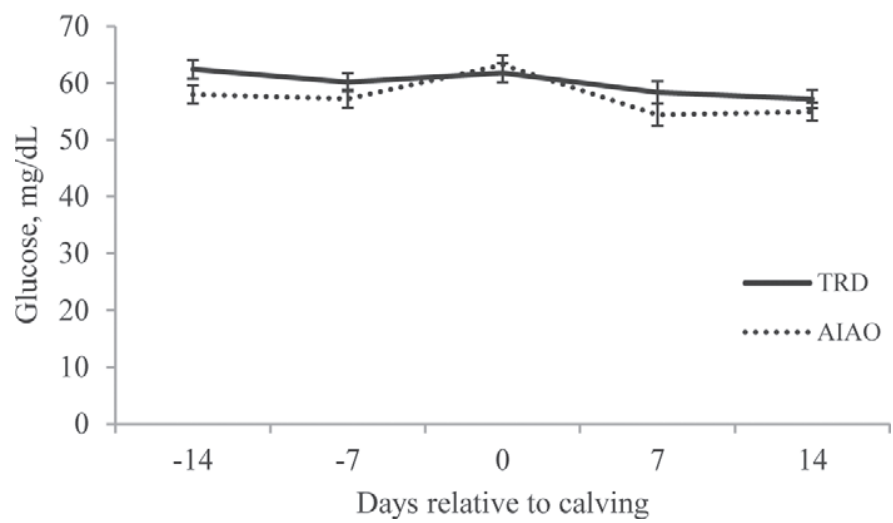

Figure 2. Concentration of glucose during the peripartum period according to treatment. Traditional prepartum grouping strategy $(\mathrm{TRD})=$ weekly entry of new cows into the prepartum pen; all-in-allout prepartum grouping strategy $(\mathrm{AIAO})=$ no entry of new cows in the prepartum pen. Target stocking density was $100 \%$ of stalls and $91.6 \%$ of headlocks. Treatment $(P=0.28)$ and the interaction between treatment and days relative to calving $(P=0.11)$ did not affect glucose concentrations.

locytes to lymphocytes were not affected by treatment. Neutrophilia has been related to stress and pain induced by castration and hot-iron dehorning (Ting et al., 2003; Doherty et al., 2007). Lobeck et al. (2012) reported that the rate of displacement from the feed bunk in the first $3 \mathrm{~h}$ after feeding was increased among TRD cows compared with AIAO cows. Furthermore, TRD cows had greater cortisol concentrations $7 \mathrm{~d}$ before calving than did AIAO cows. These findings suggest that TRD treatment resulted in more stress than the AIAO treatment and consequently in behavioral and neuroendocrine responses to stress. Nonetheless, behavioral changes in response to regrouping have been shown to be transient with behavior returning to pre-regrouping standards within a few hours or days after regrouping (von Keyserlingk et al., 2008; Lobeck et al., 2012). Therefore, it is not surprising that no alterations in hemogram parameters were observed as a consequence of treatment.

We observed no differences between AIAO and TRD cows regarding innate immune function (PMNL phagocytic and oxidative burst activities and expression of L-selectin and CD-18) or concentration of IgG antiovalbumin. The lack of effect of prepartum grouping strategy on innate immune function is surprising because TRD cows had slightly higher cortisol concentrations on $\mathrm{d} 7$ before parturition than did AIAO cows, which was likely a consequence of greater stress (Nanda et al., 1990) among TRD cows, as observed by the greater rate of agonistic behavior at the feed bunk compared with AIAO cows (Lobeck et al., 2012). Cortisol modulates immune responses through different pathways. For example, cortisol downregulates expression

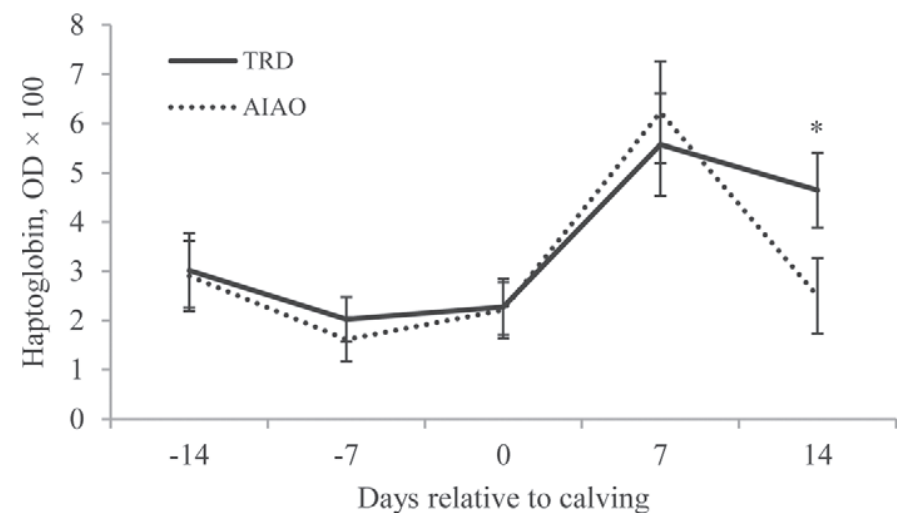

Figure 3. Haptoglobin concentration (optical density, OD, $\times 100$ ) during the peripartum period according to treatment. Traditional prepartum grouping strategy $(\mathrm{TRD})=$ weekly entry of new cows into the prepartum pen; all-in-all-out prepartum grouping strategy $(\mathrm{AIAO})=$ no entry of new cows in the prepartum pen. Target stocking density was $100 \%$ of stalls and $91.6 \%$ of headlocks. Treatment $(P=0.57)$ did not affect haptoglobin concentration, but the interaction between treatment and days relative to calving tended to $(P=0.10)$ affect haptoglobin concentration because on d 14 after calving $(*)$ TRD cows had $(P=0.05)$ greater haptoglobin concentration than AIAO cows.

of L-selectin and $\beta 2$-integrins by neutrophils, adhesion molecules involved in the trafficking of neutrophils from the endothelium to the site of infection (Burton and Kehrli, 1995a; Burton et al., 1995b, 2005), which could compromise innate immune response. Furthermore, cortisol generally inhibits synthesis of proinflammatory cytokines (IL-4, IL-6, IL-12, IFN- $\gamma$ ) and favors the secretion of antiinflammatory and immunosuppressive (IL-10) cytokines (Wiegers et al., 2005). Thus, concentration of cortisol is also expected to affect production of antibodies through the blockage of cytokines secreted by $\mathrm{CD} 4^{+} \mathrm{T}$ helper 1 or $\mathrm{CD} 4^{+} \mathrm{T}$ helper 2 cells (Salak-Johnson and McGlone, 2007).

Continuous $(24 \mathrm{~h} / \mathrm{d})$ and transient $(4 \mathrm{~h} / \mathrm{d})$ exposure of male rats to adult fight-experienced male rats resulted in significant body mass loss on d 4 and 7 after onset of challenge (Stefanski et al., 2013). Interestingly, concentrations of monocytes and granulocytes were increased on d 3 and 7 after onset of challenge in rats continuously and transiently exposed to adult fight-experienced male rats, but only rats continuously exposed to adult fightexperienced male rats had reduced concentrations of CD4 T helper and CD8 T cells (Stefanski et al., 2013). Thus, it appears that rats transiently exposed to adult fight-experienced male rats had sufficient time away from the stressor to partly alleviate the negative effects of stressful social confrontation on immune function (Stefanski et al., 2013). Transportation of calm and temperamental bulls resulted in a significant increase in cortisol concentration $24 \mathrm{~h}$ after transportation, but such an increase was more evident in temperamental bulls (Hulbert et al., 2011). Transportation resulted in 
an increase in the neutrophil:monocyte ratio at $24 \mathrm{~h}$ after transportation, which returned to pretransportation levels within $48 \mathrm{~h}$ in both calm and temperamental bulls (Hulbert et al., 2011). The percentage of neutrophils positive for phagocytosis and oxidative burst and intensity of oxidative burst were decreased in all bulls $48 \mathrm{~h}$ after transportation; calm bulls had a significant rebound effect by $96 \mathrm{~h}$ after transportation, with both the percentage of neutrophils positive for phagocytosis and oxidative burst and the intensity of oxidative burst increasing above pretransportation levels, whereas temperamental bulls had slight increases returning to pretransportation levels (Hulbert et al., 2011). Weekly regrouping of prepartum dairy cows caused only transient alterations in behavior (von Keyserlingk et al., 2008; Lobeck et al., 2012) and a minute increase in cortisol concentration on $\mathrm{d}-7$, but had no effects on concentrations of metabolites. Therefore, the social distress to which cows housed in pens with weekly regrouping were exposed caused only minor and transient alterations in behavior that do not appear to be important for immune function. The lack of differences between AIAO and TRD treatments regarding immune parameters is of particular importance to peripartum dairy cows because occurrence of retained fetal membranes (Cai et al., 1994; Miyoshi et al., 2002), metritis (Hammon et al., 2006; Silva et al., 2012), or mastitis (Burvenich et al., 2003) is associated with compromised function of macrophages and neutrophils.

Feed intake of peripartum dairy cows is reduced as cows approach the day of calving (Hayirli et al., 2002). Simultaneously, energy demands increase because of colostrogenesis. Furthermore, postpartum feed intake is insufficient to meet energy and protein requirements for colostrogenesis and lactogenesis (Grummer et al., 2004). Consequently, dairy cows undergo negative energy balance up to about 6 to 8 wk postpartum (Grummer et al., 2004). Body fat mobilization to provide energy for maintenance and lactogenesis results in elevated NEFA concentrations, and, when hepatic oxidation of NEFA is incomplete, elevated concentrations of BHBA are observed (Grummer et al., 2004). Hammon et al. (2006) demonstrated that cows that had reduced feed intake during the prepartum period had reduced neutrophil activity (myeloperoxidase activity and cytochrome $c$ reduction) during the peripartum period. This seems to be a consequence of negative energy balance associated with colostrogenesis or lactogenesis and insufficient feed intake peripartum because cows that were mastectomized 4 mo before parturition had greater expression of L-selectin prepartum, greater leukocyte count postpartum, and greater neutrophil killing activity postpartum than intact cows (Kimura et al., 1999). In the current experiment, no differences in NEFA and
BHBA concentrations or yield of ECM were observed between the AIAO and TRD treatments. Consequently, we speculate that energy status of AIAO and TRD cows was likely similar; thus, energy status should not have affected innate immune response and concentration of antibodies of cows in the AIAO and TRD treatments.

As explained previously, cows used in the current experiment represent a subgroup of cows used in a larger experiment (Silva et al., 2013). Among the cows used in the current experiment, we observed no differences in incidence of periparturient diseases between treatments. These findings are corroborated by the findings of Silva et al. (2013). Therefore, weekly regrouping of prepartum cows does not appear to cause immunosuppression or to increase the incidence of periparturient diseases.

\section{CONCLUSIONS}

Weekly regrouping of prepartum dairy cows did not affect innate immune parameters or concentration of antibodies. This indicates that weekly entry of new cows into a prepartum pen is a minor stressor that, even though it produces a neuroendocrine response (i.e., a slight increase in cortisol concentration $7 \mathrm{~d}$ before calving), was insufficient to cause immunosuppression or to affect biological functions. It is important to observe that the only stressor in the current experiment that was eliminated by the AIAO strategy was the constant regrouping, whereas the number of headlocks and stalls and availability of feed and water were ideal. Furthermore, because of differences in temperament between breeds, it is not clear whether the AIAO strategy may have a different effect on breeds of dairy cattle other than Jersey.

\section{REFERENCES}

Ballou, M. A., R. C. Gomes, S. O. Juchem, and E. J. DePeters. 2009. Effects of dietary supplemental fish oil during the peripartum period on blood metabolites and hepatic fatty acid compositions and total triacylglycerol concentrations of multiparous Holstein cows. J. Dairy Sci. 92:657-669.

Ballou, M. A., M. A. Sutherland, T. A. Brooks, L. E. Hulbert, B. L. Davis, and C. J. Cobb. 2013. Administration of anesthetic and analgesic prevent the suppression of many leukocyte responses following surgical castration and physical dehorning. Vet. Immunol. Immunopathol. 151:285-293.

Burton, J. L., and M. E. Kehrli Jr. 1995a. Regulation of neutrophil adhesion molecules, and shedding of Staphylococcus aureus in milk of cortisol- and dexamethasone-treated cows. Am. J. Vet. Res. 56:997-1006.

Burton, J. L., M. E. Kehrli Jr., S. Kapil, and R. L. Horst. 1995b. Regulation of L-selectin and CD18 on bovine neutrophils by glucocorticoids: Effects of cortisol and dexamethasone. J. Leukoc. Biol. 57:317-325.

Burton, J. L., S. A. Madsen, L. Chang, P. S. D. Weber, K. R. Buckham, R. van Dorp, M. Hickey, and B. Earley. 2005. Gene expression signatures in neutrophils exposed to glucocorticoids: A new 
paradigm to help explain "neutrophil dysfunction" in parturient dairy cows. Vet. Immunol. Immunopathol. 105:197-219.

Burvenich, C., V. Van Merris, J. Mehrzad, A. Diez-Fraile, and L. Duchateau. 2003. Severity of E. coli mastitis is mainly determined by cow factors. Vet. Res. 34:521-564.

Cai, T. Q., P. G. Weston, L. A. Lund, B. Brodie, D. J. McKenna, and W. C. Wagner. 1994. Association between neutrophil functions and periparturient disorders in cows. Am. J. Vet. Res. 55:934-943.

Cook, N. B., and K. V. Nordlund. 2004. Behavioral needs of the transition cow and considerations for special needs facility design. Vet. Clin. North Am. Food Anim. Pract. 20:495-520.

Doherty, T. J., H. G. Kattesh, R. J. Adcock, M. G. Welborn, A. M. Saxton, J. L. Morrow, and J. W. Dailey. 2007. Effects of a concentrated lidocaine solution on the acute phase stress response to dehorning in dairy calves. J. Dairy Sci. 90:4232-4239.

Ferguson, J. D., D. T. Galligan, and N. Thomsen. 1994. Principal descriptors of body condition score in Holstein cows. J. Dairy Sci. 77:2695-2703.

Grummer, R. R., D. G. Mashek, and A. Hayirli. 2004. Dry matter intake and energy balance in the transition period. Vet. Clin. North Am. Food Anim. Pract. 20:447-470.

Hammon, D. S., I. M. Evjen, T. R. Dhiman, J. P. Goff, and J. L. Walters. 2006. Neutrophil function and energy status in Holstein cows with uterine health disorders. Vet. Immunol. Immunopathol. 113:21-29.

Hayirli, A., R. R. Grummer, E. V. Nordheim, and P. M. Crump. 2002. Animal and dietary factors affecting feed intake during the prefresh transition period in Holsteins. J. Dairy Sci. 85:3430-3443.

Hulbert, L. E., J. A. Carroll, N. C. Burdick, R. D. Randel, M. S. Brown, and M. A. Ballou. 2011. Innate immune responses of temperamental and calm cattle after transportation. Vet. Immunol. Immunopathol. 143:66-74.

Kasimanickam, R., T. F. Duffield, R. A. Foster, C. J. Gartley, K. E. Leslie, J. S. Walton, and W. H. Johnson. 2004. Endometrial cytology and ultrasonography for the detection of subclinical endometritis in postpartum dairy cows. Theriogenology 62:9-23.

Kimura, K., J. P. Goff, and M. E. Kehrli Jr. 1999. Effects of the presence of the mammary gland on expression of neutrophil adhesion molecules and myeloperoxidase activity in periparturient dairy cows. J. Dairy Sci. 82:2385-2392.

Kojima, C. J., H. G. Kattesh, M. P. Roberts, and T. Sun. 2008. Physiological and immunological responses to weaning and transport in the young pig: Modulation by administration of porcine somatotropin. J. Anim. Sci. 86:2913-2919.

Lacetera, N., U. Bernabucci, D. Scalia, B. Ronchi, G. Kuzminsky, and A. Nardone. 2005. Lymphocyte functions in dairy cows in hot environment. Int. J. Biometeorol. 50:105-110.

LeBlanc, S. 2010. Monitoring metabolic health of dairy cattle in the transition period. J. Reprod. Dev. 56:S29-S35.

Lobeck, K. M., M. I. Endres, P. R. B. Silva, and R. C. Chebel. 2012. Effect of prepartum grouping strategy on agonistic behavior of dairy cows. J. Dairy Sci. 95(Suppl. 2):219. (Abstr.)

Mallard, B. A., L. C. Wagter, M. J. Ireland, and J. C. M. Dekkers. 1997. Effects of growth hormone, insulin-like growth factor-I, and cortisol on periparturient antibody response profiles of dairy cattle. Vet. Immunol. Immunopathol. 60:61-76.
McDougall, S., R. Macaulay, and C. Compton. 2007. Association between endometritis diagnosis using a novel intravaginal device and reproductive performance in dairy cattle. Anim. Reprod. Sci. 99:9-23.

Mendonça, L. G. D., N. B. Litherland, M. C. Lucy, D. H. Keisler, M. A. Ballou, L. B. Hansen, and R. C. Chebel. 2013. Comparison of innate immune responses and somatotropic axis components of Holstein and Montbéliarde-sired crossbred dairy cows during the transition period. J. Dairy Sci. 96:3588-3598.

Miyoshi, M., Y. Sawamukai, and T. Iwanaga. 2002. Reduced phagocytotic activity of macrophages in the bovine retained placenta. Reprod. Domest. Anim. 37:53-56.

Moberg, G. P. 2000. Biological response to stress: Implications for animal welfare. Pages 1-21 in The Biology of Animal Stress: Basic Principles and Implications for Animal Welfare. G. P. Moberg and J. A. Mench, ed. CABI Publishing, New York, NY.

Nanda, A. S., H. Dobson, and W. R. Ward. 1990. Relationship between an increase in plasma cortisol during transport-induced stress and failure of oestradiol to induce a luteinising hormone surge in dairy cows. Res. Vet. Sci. 49:25-28.

Orth, R. 1992. Sample day and lactation report. In Dairy Herd Improvement Association 200 Fact Sheet A-2. Mid-States Dairy Records Processing Center (DRPC), Ames, IA.

Salak-Johnson, J. L., and J. J. McGlone. 2007. Making sense of apparently conflicting data: Stress and immunity in swine and cattle. J. Anim. Sci. 85:E81-E88.

Silva, P. R. B., J. G. N. Moraes, L. G. D. Mendonça, G. Nakagawa, and R. C. Chebel. 2012. Peripartum metabolic, immune, and hematological parameters of Jersey cows diagnosed with periparturient diseases. J. Dairy Sci. 95(Suppl. 2):438. (Abstr.)

Silva, P. R. B., J. G. N. Moraes, L. G. D. Mendonça, A. A. Scanavez, G. Nakagawa, J. Fetrow, M. I. Endres, and R. C. Chebel. 2013. Effects of weekly regrouping of prepartum dairy cows on metabolic, health, reproductive, and productive parameters. J. Dairy Sci. 96:4436-4446. http://dx.doi.org/10.3168/jds.2012-6464.

Sprecher, D. J., D. E. Hostetler, and J. B. Kaneene. 1997. A lameness scoring system that uses posture and gait to predict dairy cattle reproductive performance. Theriogenology 47:1179-1187.

Stefanski, V., S. K. Hemschemeier, K. Schunke, A. Hahnel, C. Wolff, and R. H. Straub. 2013. Differential effect of severe and moderate social stress on blood immune and endocrine measures and susceptibility to collagen type II arthritis in male rats. Brain Behav. Immun. 29:156-165.

Ting, S. T. L., B. Earley, and M. A. Crowe. 2003. Effect of repeated ketoprofen administration during surgical castration of bulls on cortisol, immunological function, feed intake, growth and behavior. J. Anim. Sci. 81:1253-1264.

von Keyserlingk, M. A. G., D. Olenick, and D. M. Weary. 2008. Acute behavioral effects of regrouping dairy cows. J. Dairy Sci. 91:10111016.

Wiegers, G. J., I. E. M. Stec, P. Sterzer, and J. M. H. M. Ruel. 2005. Glucocorticoids and the immune response. Pages 175-191 in Handbook of Stress and the Brain. T. Steckler, N. H. Kalin, and J. M. H. M. Reul, ed. Elsevier, Amsterdam, the Netherlands. 